\title{
Successful Percutaneous Coronary Interventionin a Patient with Dextrocardia and Situs Inversus-a case report
}

\author{
SYED ALI AHSAN, HAFIZUR RAHMAN, AHMED SHAFIQUL HOSSAIN, \\ MD. ABU SIDDIQUE, MANZOOR MAHMOOD
}

Department of Cardiology, Univesity Cardiac Center, Bangabandhu Sheikh Mujib Medical University, Shahbag, Dhaka, Bangladesh.

Address for Correspondence: Prof Syed Ali Ahsan, Department of Cardiology, Univesity Cardiac Center, Bangabandhu Sheikh Mujib Medical University, Shahbag, Dhaka, Bangladesh, E-mail: draliahsan@yahoo.com

\begin{abstract}
:
Dextrocardia is a rare congenital anomaly of development characterized by a mirror- image position of the heart. Unlike dextrocardia with situs solitus or ambiguus, the coincidence of congenital heart disease is relatively low among dextrocardic patients with situs inversus. However, patients with dextrocardia may suffer from coronary heart disease as do people with normally positioned hearts. Few cases of coronary angiography and percutaneous coronary intervention in patients with dextrocardia have been reported. This is a case of a 48-year-old male patient with dextrocardia who developed unstable angina and was able to undergo diagnostic catheterization and percutaneous coronary intervention. We successfully performed percutaneous coronary angioplasty followed by coronary stenting to the left circumflex artery (LCX) and described our experience in the selection of the guiding catheters (standard preformed catheters), angiographic image acquisition (mirror image views with subtle modification) and coronary catheter engaging techniques (opposite-direction catheter rotations).
\end{abstract}

Key Words:ö Dextrocardia Situs inversus, Percutaneous coronary intervention, Coronary stenting

\section{Introduction:}

Situs inversus with dextrocardia is a rare congenital anomaly of development characterized by a mirror-image position of the heart and abdominal viscera. ${ }^{1,2}$ It occurs rarely in the general population, with an estimated incidence of $1: 8,000$ to $1: 10,000.1$ Patients with dextrocardia usually have structurally normal hearts and experience normal longevity ${ }^{2}$ but may suffer from acquired heart disease such as coronary heart diseases as do people with normal positioned hearts. ${ }^{3-5}$ Few cases of coronary angiography and percutaneous coronary intervention (PCI) in patients with dextrocardia have been reported. ${ }^{3}$ To the best of our

knowledge, this is the first report of successful coronary acoronary stenting in a patient with dextrocardia with situs inversus in University Cardiac Center, BSMMU, Bangladesh. We have described a case of percutaneous transluminal coronary angioplasty (PTCA) followed by coronary stenting to the left circumflex artery (LCX) and our experience in the selection of the guiding catheters, angiographic image acquisition and coronary catheter engaging technique.

\section{Case Report:}

A 48-yr-old hypertensive male pre-sented with acute persistent chest pain of approximately $8 \mathrm{~h}$ duration in March 2012. He was a known case of situs inversus with dextrocardia and recently diagnosed as a case of diabetes mellitus and dyslipidaemia. Clinical examination revealed a right-sided apex beat and no left ventricular third heart sound or murmur. His random blood glucose was $231 \mathrm{mg} / \mathrm{dl}$ and lipids showed total cholesterol was $128 \mathrm{mg} \%$, HDL was $20 \mathrm{mg} \%$, LDL was $59 \mathrm{mg} \%$, and triglycerides were $247 \mathrm{mg} \%$. ECG showed a negative $\mathrm{P}$ wave in the I and aVL limb leads, a positive $\mathrm{R}$ wave in the aVR limb leads, a prominent $\mathrm{S}$ wave in the left side chest leads and a prominent $\mathrm{R}$ wave in the right sided chest leads (Figure 1), which is suggestive of situs inversus with dextrocardia.

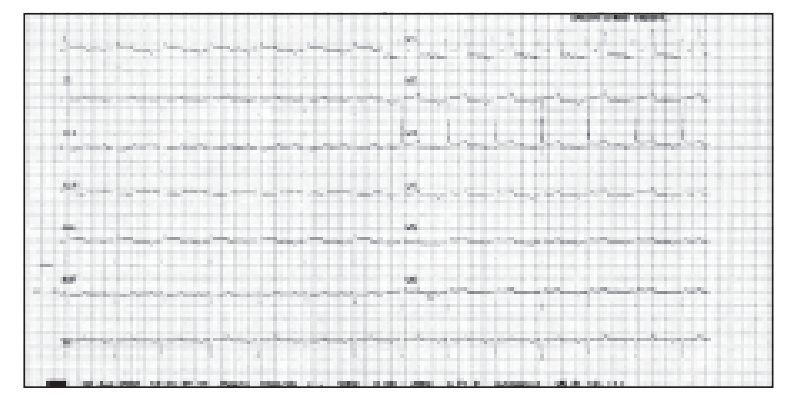

Fig.-1: Negative $P$ wave in the I and aVL limb leads, $a$ positive $R$ wave in the aVR limb leads, a prominent $S$ wave in the left side chest leads and a prominent $R$ wave in the right sided chest leads.

A right sided 12 leads ECG showed ST depression in Lead-I,aVL. V5 and V6.(Figure 2) 


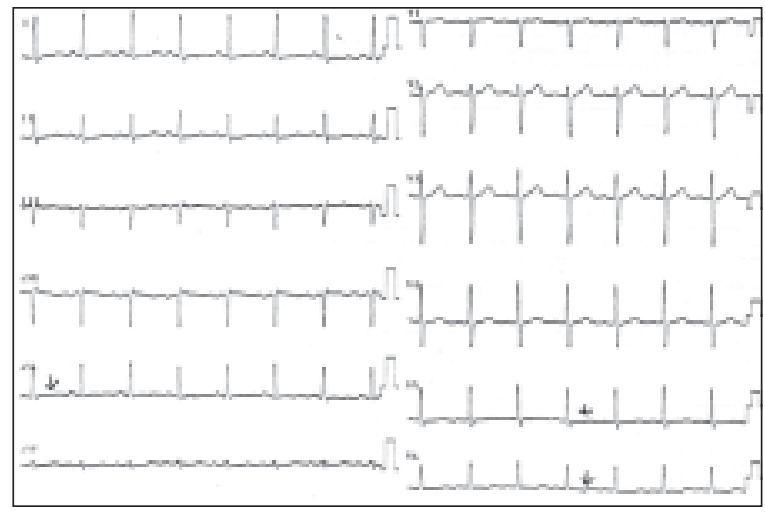

Fig.-2: right sided 12 leads ECG showed ST depression in Lead-I,aVL. V5 and V6.

A 2-D echocardiogram showed situs inversus and dextrocardia, no regional wall motion abnormality and a left ventricular ejec-tion fraction of 0.60 .A chest skiagram revealed situs inversus and dextrocardia. He underwent coro-nary angiography on March 2012. The left coronary was easily cannulated with a Judkins Left 3.5, $6 \mathrm{~F}$ catheter. The left main coronary artery was normal . LAD had 20\% stenosis in mid part and another $20 \%$ stenosis in distal part. There was $90 \%$ stenosis in distal LCX.(Figure 3). The RCA was cannulated with anti-clockwise rotation of a Judkins Right 3.5, 6F catheter. Initially, there was difficulty in local-izing the RCA ostium in the aortic root, but later it was selectively cannulated and showed normal and disease free.

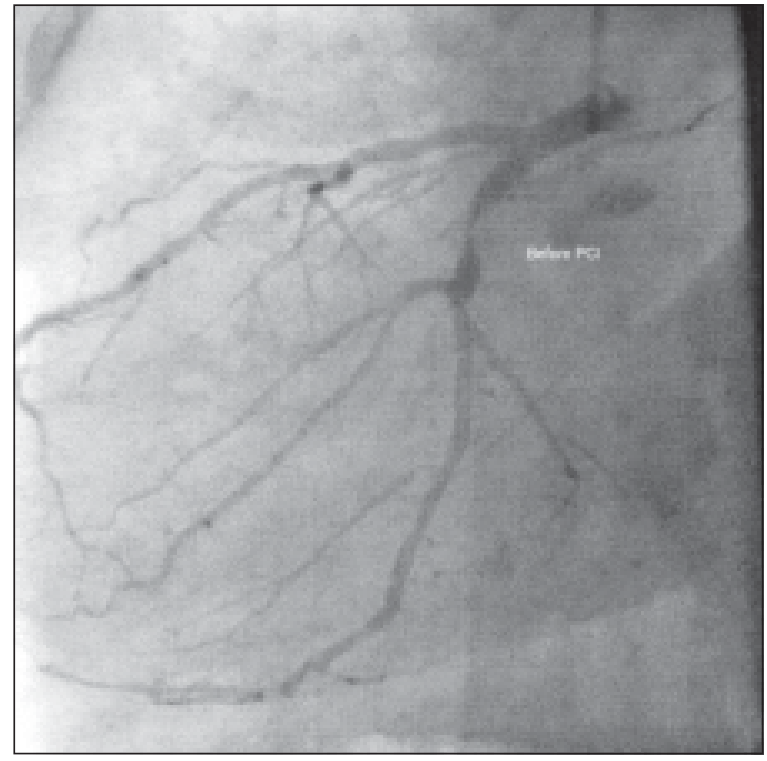

Fig.-3: $C A G$ before PCI
PCI and stenting to LCX was done on April 2012. LMCA was selectively cannulated with an extra support guide catheter (ECR 3.5, 6F, Medtronic), but this was not successful despite an anti-clockwise rota-tion and changing the angulation from $\mathrm{LAO} 60^{\circ}$ to mirror image RAO $60^{\circ}$. An Extra Support guide wire was introduced and advanced distally across the lesion successfully. The lesion was predilated with $2.5 \times 10 \mathrm{~mm}$ balloon at 10 ATM pressure. Then a Cobalt-Chromium stent of $3.5 \mathrm{X}$ $13 \mathrm{~mm}$ size was deployed at 10 ATM pressure which resulted in TIMI-3 flow (Figure 3C). The total fluoroscopy time of the procedure was $32 \mathrm{~min}$. He had an uneventful recovery and was discharged after 3 days on dual antiplatelets, atorv-astatin, anti-hypertensive and antidiabetic drugs. At 01 month of follow-up, he was asymptomatic.

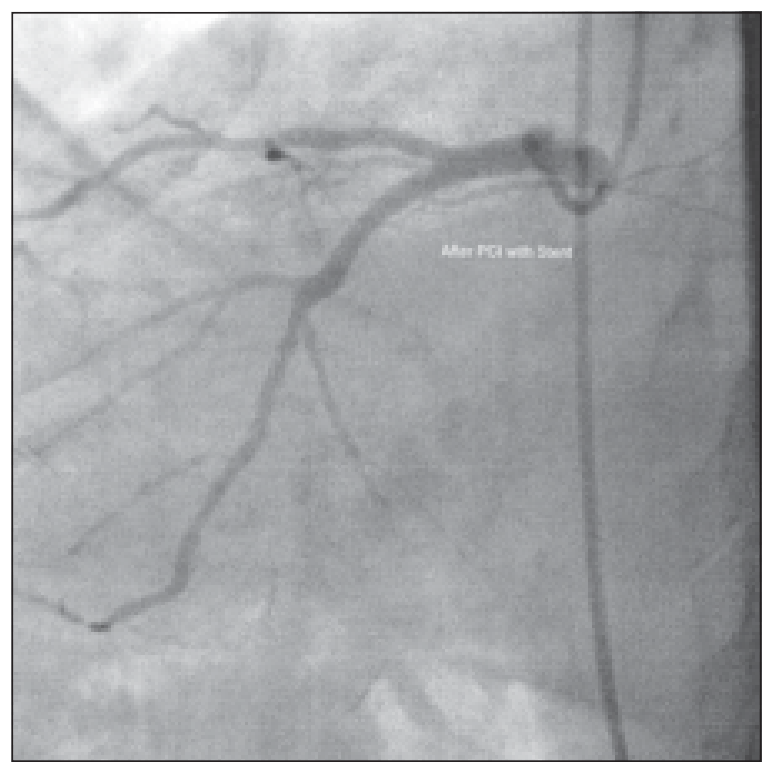

Fig.-4: CAG after PCI

\section{Discussion:}

Situs inversus with dextrocardia is a rare congenital anom-aly and presents in approximately one per 10000 individ-uals ${ }^{1}$. In the absence of other structural heart disease, the life expectancy is usually normal. The association of CAD in these patients is the same as in the general population ${ }^{4}$, Hence, even elderly patients with this rare anomaly have been subjected to successful percutane-ous or surgical intervention of CAD, as reported in the literature ${ }^{6,7}$. The first cardiac catheterisation in dextrocardia was reported in $1973,{ }^{8}$ the first coronary artery bypass surgery in $1980^{9}$ and the first percutaneous intervention in dextrocardia was performed in $1987 .{ }^{10}$ The selective cannulation of the 
RCA might be difficult because of mirror images, for which the op-erator is not accustomed and also one has to rotate the catheter anticlockwise in the aorta, instead of the routine clockwise rotation for cannulation of the RCA $^{9}$. A double-inversion technique of Goel ${ }^{11}$, in which all angiographic pictures are normalized to the standard conventional pictures, as seen in a normally located heart by doing a combination of a right-left re-versal of the image on the monitor using the "horizontal sweep reverse" function during acquisition and a reversed RAO/ LAO angle selection, can help in better localization and delineation of the coronary anatomy. This case report is dedicated to the young and new cardiologist who may face this type of cases rarely for their future reference.

\section{References:}

1. Rosenberg HN, Rosenberg IN. Simultaneous association of situs inversus, coronary heart disease and hiatus hernia; re-port of a case and review of literature. Ann Intern Med 1949; 30: 851-859

2. Perloff JK. The Clinical Recognition of Congenital Heart Disease, 3rd ed. Philadelphia: WB Saunders Co., 1978;19-42.
3. Blankenship JC, Ramires JA. Coronary arteriography in patients with dextrocardia. Cathet Diagn 1991; 23: 103-106

4. Hynes KM, Gau GT, Titus JL. Coronary heart disease in si-tus inversus totalis. Am J Cardiol 1973; 31: 666-69

5. Pfashkin D, Stein E, Warbasse JR. Congenital dextrocardia, with anterior wall myocardial infarction. Am Heart J 1967;74:262-7.

6. Bonde P, Campalani GF. Myocardial revascularization for situs inversus totalis and dextrocardia. Interact Cardiovasc Thorac Surg 2003; 2: 486-88

7. Saadi EK, Dussin LH, Nicolao A, Zago AJ. Coronary artery bypass grafting in a patient with situs inversus totalis and dextrocardia. Rev Bras Cir 2007; 22: 346-48

8. Ettinger PO, Brancato R, Penn D. Dextrocardia, anteroseptal infarction and fascicular block. Chest 1975;68:229-30.

9. Irvin RG, Ballenger JF. Coronary artery bypass surgery in a patient with situs inversus. Chest 1982;81:380-81.

10. Moreyra AE, Saviano GJ, Kostis JB. Percutaneous transluminal coronary angioplasty in situs inversus. Cathet Cardiovasc Diagn 1987;13:114-16.

11. Goel PK. Double-inversion technique for coronary angi-ography viewing in dextrocardia. Catheter Cardiovasc Interv 2005; 66: 281-85. 